NASA/TM-2000-210592

\title{
2001017593
}

\section{Update on the NASA GRC Stirling Technology Development Project}

Lanny G. Thieme and Jeffrey G. Schreiber

Glenn Research Center, Cleveland, Ohio 
Since its founding, NASA has been dedicated to the advancement of aeronautics and space science. The NASA Scientific and Technical Information (STI) Program Office plays a key part in helping NASA maintain this important role.

The NASA STI Program Office is operated by Langley Research Center, the Lead Center for NASA's scientific and technical information. The NASA STI Program Office provides access to the NASA STI Database, the largest collection of aeronautical and space science STI in the world. The Program Office is also NASA's institutional mechanism for disseminating the results of its research and development activities. These results are published by NASA in the NASA STI Report Series, which includes the following report types:

- TECHNICAL PUBLICATION. Reports of completed research or a major significant phase of research that present the results of NASA programs and include extensive data or theoretical analysis. Includes compilations of significant scientific and technical data and information deemed to be of continuing reference value. NASA's counterpart of peerreviewed formal professional papers but has less stringent limitations on manuscript length and extent of graphic presentations.

- TECHNICAL MEMORANDUM. Scientific and technical findings that are preliminary or of specialized interest, e.g., quick release reports, working papers, and bibliographies that contain minimal annotation. Does not contain extensive analysis.

- CONTRACTOR REPORT. Scientific and technical findings by NASA-sponsored contractors and grantees.
- CONFERENCE PUBLICATION. Collected papers from scientific and technical conferences, symposia, seminars, or other meetings sponsored or cosponsored by NASA.

- SPECIAL PUBLICATION. Scientific, technical, or historical information from NASA programs, projects, and missions, often concerned with subjects having substantial public interest.

- TECHNICAL TRANSLATION. Englishlanguage translations of foreign scientific and technical material pertinent to NASA's mission.

Specialized services that complement the STI Program Office's diverse offerings include creating custom thesauri, building customized data bases, organizing and publishing research results ... even providing videos.

For more information about the NASA STI Program Office, see the following:

- Access the NASA STI Program Home Page at http://www.sti.nasa.gov

- E-mail your question via the Internet to help@sti.nasa.gov

- Fax your question to the NASA Access Help Desk at 301-621-0134

- Telephone the NASA Access Help Desk at 301-621-0390

- Write to:

NASA Access Help Desk

NASA Center for AeroSpace Information 7121 Standard Drive

Hanover, MD 21076 


\section{Acknowledgments}

The authors would like to acknowledge the Office of Space Science and the Office of Aerospace Technology at NASA Headquarters for providing funding for this project.

\section{Available from}

NASA Center for Aerospace Information 7121 Standard Drive Hanover, MD 21076

Price Code: A03
National Technical Information Service 5285 Port Royal Road Springfield, VA 22100 Price Code: A03 
NASA/TM-2000-210592

\section{Update on the NASA GRC Stirling Technology Development Project}

Lanny G. Thieme and Jeffrey G. Schreiber

Glenn Research Center, Cleveland, Ohio

Prepared for the

Space Technology and Applications International Forum sponsored by the American Institute of Physics

Albuquerque, New Mexico, February 11-15, 2001

National Aeronautics and

Space Administration

Glenn Research Center 


\title{
Update on the NASA GRC Stirling Technology Development Project
}

\author{
Lanny G. Thieme and Jeffrey G. Schreiber \\ National Aeronautics and Space Administration \\ Glenn Research Center \\ Cleveland, Ohio 44135
}

\begin{abstract}
The Department of Energy, NASA Glenn Research Center (GRC), and Stirling Technology Company (STC) are developing a free-piston Stirling convertor for a Stirling radioisotope power system (SRPS) to provide spacecraft on-board electric power for NASA deep space missions. The SRPS has recently been identified for potential use on the Europa Orbiter and Solar Probe Space Science missions. Stirling is also now being considered for unmanned Mars rovers. NASA GRC is conducting an in-house project to assist in developing the Stirling convertor for readiness for space qualification and mission implementation. As part of this continuing effort, the Stirling convertor will be further characterized under launch environment random vibration testing, methods to reduce convertor electromagnetic interference (EMI) will be developed, and an independent performance verification will be completed. Convertor life assessment and permanent magnet aging characterization tasks are also underway. Substitute organic materials for the linear alternator and piston bearing coatings for use in a high radiation environment have been identified and have now been incorporated in Stirling convertors built by STC for GRC. Electromagnetic and thermal finite element analyses for the alternator are also being conducted. This paper discusses the recent results and status for this NASA GRC in-house project.
\end{abstract}

\section{INTRODUCTION}

The Department of Energy (DOE), NASA Glenn Research Center (GRC), and Stirling Technology Company (STC) of Kennewick, WA are developing a Stirling convertor for a Stirling radioisotope power system (SRPS) to provide spacecraft on-board electric power for NASA deep space missions. The SRPS is being evaluated as an alternative to replace radioisotope thermoelectric generators (RTGs) with a high-efficiency power source and has recently been identified for potential use on the Europa Orbiter and Solar Probe missions now scheduled for launch in the 20062007 timeframe. The SRPS is also being considered for unmanned Mars rovers, especially where mission profiles may exclude the use of photovoltaic power systems such as exploration at high Martian latitudes or for missions of long duration.

The efficiency of the SRPS, about $20-25 \%$, will reduce the required amount of radioisotope by a factor of 3 or more compared to RTGs. This significantly reduces radioisotope cost, radiological inventory, and system cost and provides efficient use of scarce radioisotope resources.

STC has designed, fabricated, and completed first testing of the 55-We Technology Demonstration Convertor (TDC) under contract to DOE (White, 2000). Based on a recently completed DOE/NASA technology assessment (Furlong, 2000), the TDC has been baselined by DOE for use in the SRPS. Both design convertor power and efficiency have been demonstrated by STC, and performance has been mapped as a function of hot-end and coldend temperatures. Long life has also been demonstrated on a similar STC 10-We radioisotope terrestrial convertor, RG-10, that has been on life test at STC for over 60,000 hours (6.8 years) with no convertor maintenance and no degradation in performance. An assessment of the free-piston Stirling convertor as a long life space power convertor is given in (Schreiber, 2000). NASA GRC is providing technical consulting for the TDC development effort under an Interagency Agreement with DOE. 
As part of the overall Stirling radioisotope convertor development, GRC is addressing key technology issues through the use of two NASA Phase II Small Business Innovation Research (SBIR) contracts with STC (Thieme, 2000a). Under the first SBIR, STC demonstrated a synchronous connection of two thermodynamically independent Stirling convertors and a 40 to 50 fold reduction in vibrations compared to an unbalanced convertor. This connection method is now being used to connect the TDC convertors. The second SBIR contract is for the development of an Adaptive Vibration Reduction System that further reduces vibrations under normal operating conditions and will add the ability to adapt to any changing convertor conditions over the course of a mission.

GRC is also conducting an in-house project to assist in developing the Stirling convertor for readiness for space qualification and mission implementation (Thieme, 2000b). As part of the DOE/NASA technology assessment, GRC conducted a series of independent evaluations and tests to determine the technology readiness of the TDC. Key areas evaluated by GRC included: 1) radiation tolerance of the convertor organic materials, 2) random vibration testing of the Stirling convertor in the NASA GRC Structural Dynamics Lab to simulate operation in the launch environment 3) electromagnetic interference and compatibility (EMI/EMC) of the convertor operating in the NASA GRC EMI/EMC lab, 4) independent Failure Modes, Effects, and Criticality Analysis (FMECA) and life and reliability assessment, and 5) SRPS cost estimate.

As part of the continuing GRC in-house effort, the Stirling convertor will be further characterized under launch environment random vibration testing, methods to reduce convertor EMI will be developed, and an independent performance verification will be completed. Convertor life assessment and permanent magnet aging characterization tasks are underway. Substitute organic materials for the linear alternator and piston bearing coatings for use in a high radiation environment have been identified and have now been incorporated in Stirling convertors built by STC for GRC. Electromagnetic and thermal finite element analyses for the alternator are also being conducted. This paper will discuss the recent results and status for the NASA GRC in-house project.

\section{INDEPENDENT PERFORMANCE VERIFICATION OF 55-We TDC'S}

An in-house Stirling test facility has been established for testing 55-We TDC convertors. Two 55-We TDC's have been built by STC and delivered to NASA GRC. The test setup for these two convertors is shown in figures 1 and 2 .

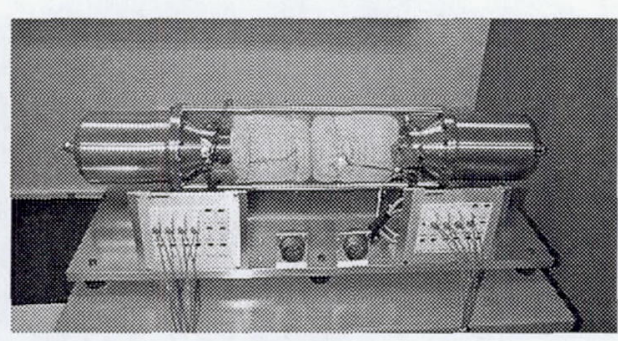

FIGURE 1. Dual-Opposed 55-We TDC Convertors at NASA GRC.

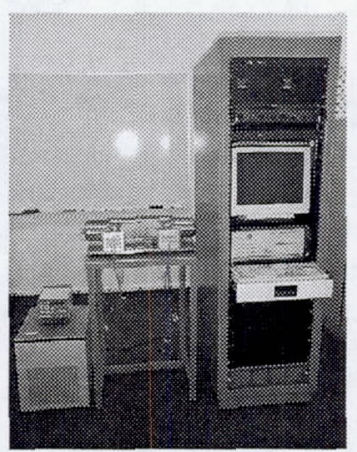

FIGURE 2. NASA GRC TDC Test Setup.
Two additional TDC's are now being assembled by STC for GRC. All four GRC TDC's are essentially identical in configuration and thus should allow comparison of performance between convertors. These TDC's are the first to incorporate radiation-hard organic materials for the piston bearing coatings and bumpers and in the linear alternator. The TDC's will be tested in both single and dualopposed configurations; the dual-opposed testing will use a hot-end to hot-end arrangement as will be used in the SRPS.

An independent verification of convertor performance and mapping will first be done with the TDC's operating over a range of hot-end and cold-end temperatures. The second set of TDC's will be run for about 1000 hours to approximate the expected pre-launch operation of a convertor and to age the convertor organic materials (this aging is expected to be complete after this test time). Then, the convertors will be vibration tested in the random vibration launch environment in the NASA GRC Structural Dynamics Lab. Following this, they will be endurance tested for at least 2000 hours.

These TDC's will also be used for both launch environment and electromagnetic interference/compatibility (EMI/EMC) characterization testing (see section later in this paper) and as demonstration test beds for proving the functionality of the radiationhard organic materials. GRC will also be receiving two 350 -We STC convertors that were built under one of the NASA Phase II SBIR's. These convertors were used at STC for developing the system connection for multiple convertors and the Adaptive Vibration Reduction System (AVRS) (Thieme, 2000a). These convertors will be used at GRC to support controls technology development, including expected further development of the AVRS. 


\section{PERMANENT MAGNET AGING TESTS}

NdFeB permanent magnets are used in the TDC linear alternators. Characterization testing of appropriate NdFeB magnets was first done using an existing NASA GRC test rig that was developed during previous Stirling research as part of the SP-100 nuclear power system program. The characterization testing of nine NdFeB magnet types from three different manufacturers has been completed with B-H curves for two different samples of each magnet type measured over a range of temperatures from room temperature to $423 \mathrm{~K}$ (Thieme, 2000b).

Short-term and long-term aging tests with margin on the magnet operating temperature and in a demagnetizing field are now being run to quantify any potential magnet degradation with time and temperature. Such degradation, if any, could affect both the remanent magnetization and the demagnetization resistance.

Based on the $\mathrm{NdFeB}$ characterization tests, several $\mathrm{NdFeB}$ magnet types have been selected for short-term magnet aging tests. Preliminary short-term aging tests have been completed using the magnet characterization rig. Three $\mathrm{NdFeB}$ magnet types have been tested for about 100 hours at $393 \mathrm{~K}$ and in a 6-kOe demagnetizing field. No measurable changes in magnet characteristics were found after these tests.

A magnet aging test fixture has been designed and fabricated by KJS Associates Inc., Indianapolis, IN and has recently been installed at GRC. This test fixture allows up to 10 magnet samples to be tested at once in an inert gas. The inert gas will prevent oxidation effects from occurring over the test period and influencing the results. In actual operation, the magnets are located in the helium environment of the convertor. The samples will be maintained at a selected temperature and with a fixed DC demagnetizing field applied. This demagnetizing field will be chosen based on the maximum demagnetizing field that the magnets see in operation. The aging fixture is shown in figure 3. Figure 4 shows the fixture opened with the locations for the test magnets visible in the right half and one of the pole pieces shown on the left. Finally, figure 5 shows the fixture installed in an electromagnet for the actual testing.

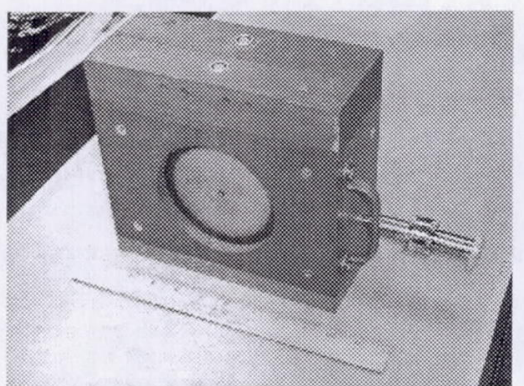

FIGURE 3. Magnet Aging Test Fixture.

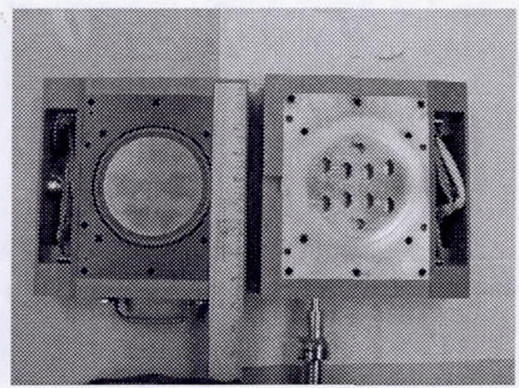

FIGURE 4. Opened Magnet Aging Test Fixture.

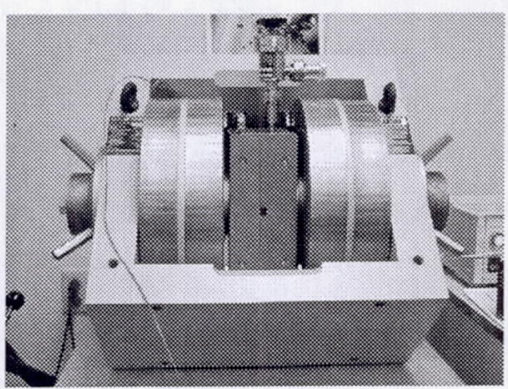

FIGURE 5. Magnet Aging Test Fixture in Electromagnet.

Baseline tests of the magnet samples to be used in the further aging tests have been completed with baseline characterizations done at both 393 and $423 \mathrm{~K}$. Further short-term ( 200 hours) aging tests with the aging test rig (figure 5) have just been started at $423 \mathrm{~K}$ to see if any measurable aging is found at this higher temperature. Either one or two NdFeB magnet types will then be chosen for the long-term aging tests. It is planned to run the long-term tests for a minimum of 12,000 hours. Magnet samples will be periodically removed from the test rig to quantify the rate of aging. These results will be used to project magnet characteristics over the 6-15 year mission lifetimes.

\section{HEATER HEAD LIFE ASSESSMENT}

Heater head life is a critical element for achieving the 100,000+ hour life of the convertor. NASA GRC materials and structures personnel have developed an approach to characterize the long-term durability of the heater head 
using relatively short-term extrapolation methods (Bartolotta, 2000). Life prediction models have been identified, and a heater head finite element analysis (FEA) model has been completed. Thermal and structural FEA studies are now being done. The heater head material, Inconel 718 (IN718), will be characterized in its final processing condition (i.e. thickness, braze cycles, and heat treatment) that will be used in fabricating the heater heads of the flight convertors. The IN718 will be characterized for creep ( $<20,000$ hours), low cycle fatigue, thermal, and tensile strength. Structural benchmark testing will also be done consisting of accelerated life tests on prototypical heater heads. Results of this testing and the IN718 material tests will be used to calibrate and validate the life prediction model. This calibrated model will then be used to project the heater head lifetime. Successful completion of these efforts is expected to give high confidence in the ability of the heater head to meet the operational life requirements.

Creep testing has been initiated for the IN718 heater head material, including studying the effect of wall thickness to grain size ratio. Much of the creep database for input to the model will be drawn from the literature, but long lifetime data pertinent to the thin walls of the Stirling convertor will need to be taken from the actual material to be used in the heater head. NASA GRC has placed an order for the IN718 that will be used to build all near-term flight convertors and conduct the associated material testing. Delivery is expected soon, and property testing on this material will then be started. A high temperature, high pressure test system has been designed and is now being assembled for the heater head accelerated life tests. This rig is shown in figure 6. This will apply both temperature gradients and pressure conditions based on those in the actual convertor. Elevated pressure and/or temperature conditions will be used to accelerate the testing. The heater heads will be fabricated from the flight convertor material.

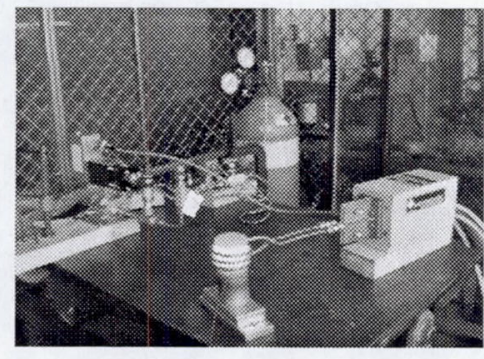

FIGURE 6. Heater Head

Structural Benchmark Testing.

An evaluation of the joining methods used in the convertor is also being conducted. Critical joints will be thermally aged and microstructurally investigated. This will include, in particular, the critical closeout hermetic seal. A test setup to evaluate the hermetic seal has been designed.

\section{CONVERTOR LAUNCH ENVIRONMENT AND EMI/EMC CHARACTERIZATIONS}

A first characterization of the TDC in the expected random vibration launch environment was completed in the NASA GRC Structural Dynamics Laboratory (SDL) as part of the DOE/NASA Stirling technology assessment (Goodnight, 2000 and Thieme, 2000b). The TDC successfully passed workmanship, flight acceptance, and qualification random vibration levels (12.3 Grms max.) while operating at full power and full stroke. Vibrations were applied in both axial and transverse orientations. TDC power and efficiency were identical before and after each test.

A series of further launch environment tests are now planned. Potential tests include a test with dual-opposed TDC's in the Microgravity Emissions Lab (part of the SDL) to characterize the sensitivity of TDC vibrations and performance to alignment and a random vibration test of a single TDC without its pressure vessel to better understand the convertor internal operation under launch environment conditions. Removing the pressure vessel allows instrumenting and monitoring of the moving components and internal structure during the test. Initial analysis indicates that motoring the non-pressurized convertor should produce frequencies near its standard $80 \mathrm{hz}$ (60-70 hz expected) so a realistic test should be feasible. Random vibration tests with dual-opposed TDC's and an engineering mounting structure are also planned. The results will provide inputs to system integrators on the sensitivities of TDC operation in the launch environment to variations in the mounting structure. Finally, a random vibration test will be completed with dual-opposed TDC's with a prototypical mounting structure.

As part of the DOE/NASA Stirling technology assessment, two operational TDC's were characterized for electromagnetic interference and compatibility (EMI/EMC) in the NASA GRC EMI/EMC lab (Thieme, 2000b). Based on the test data, the TDC's would meet the requirements for missions such as Europa Orbiter and Pluto Kuiper Express but would exceed the Solar Probe magnetic and electric field requirements (driven by the science package). Harmonic content was largely a function of the current waveform, which is expected to be much more sinusoidal with few harmonics in the flight unit compared to the TDC operating with its laboratory controller. It was then concluded that significant improvements are possible by optimizing wiring layout, providing counter-loops

NASA/TM-2000-210592 
when necessary, and adding magnetic shielding. It is expected that these modifications should also allow use of the convertor for such missions as Solar Probe. Methods to reduce the TDC EMI will now be more clearly identified and evaluated. Further TDC characterization tests will be completed to assist in this process.

\section{MULTI-DIMENSIONAL CFD PERFORMANCE CODE}

A grant has recently been awarded to Cleveland State University (CSU) to develop a multi-dimensional Stirling computational fluid dynamics (CFD) code to significantly improve Stirling loss predictions and assist in identifying convertor areas for further improvements. The University of Minnesota and Gedeon Associates are teamed with CSU for this effort.

CSU and NASA GRC collaborated on related loss understanding and initial two-dimensional CFD code investigations previously under GRC Stirling efforts in support of the SP-100 program (Tew, 1992). This research included both experimental and analytical studies to improve the understanding of various key performance losses in a Stirling convertor. The previous CSU CFD efforts included modeling oscillating inlet and outlet velocity conditions; sudden changes in channel cross sections; different low Reynolds number, k-epsilon turbulent models; laminar, transitional, and turbulent flow in a pipe; incompressible flow with moving boundaries; and compressible flow with moving boundaries. The University of Minnesota and Gedeon Associates, as well as a number of other researchers, also participated in this earlier Stirling loss understanding research.

CSU will now start from these previous efforts and develop a complete two-dimensional CFD code for Stirling convertors of the general configuration of the Stirling radioisotope space power convertors. The code results will be compared with test data and other codes as possible. Key existing one-dimensional Stirling performance and design codes agree reasonably well with each other in terms of overall performance but can differ significantly in the magnitude of specific internal losses. Also, one-dimensional codes do not rigorously model manifolds between heat exchangers and expansion/compression spaces in the convertor. In certain cases, hardware experiences have shown that large performance gains can be made by varying manifolds and heat exchanger designs to improve flow distributions in the heat exchangers. It is expected that this CFD code should give a significant improvement in the understanding of these losses and convertor design areas and, thus, help lead to further performance improvements.

\section{OTHER TASKS}

Lightweight linear alternators with high efficiency are a key to obtaining the potential of the Stirling convertor for the radioisotope power system. NASA GRC has been developing FEA tools for performing various linear alternator analyses, including thermal and electromagnetic analyses and evaluating design configurations. A threedimensional magnetostatic model of the TDC linear alternator has been developed using Ansoft's Maxwell 3D finite element method software (Geng, 2000). A thermal analysis and initial electromagnetic calculations of the TDC linear alternator open circuit voltage and margin against demagnetization have been completed. Dynamic circuit simulation software capable of working with Maxwell 3D should be available soon; this will allow complete simulations under load. These complete circuit results will also be compared with simulations that are planned with the Saber simulation code.

Future missions for the SRPS include a possible mission to the Jupiter moon Europa. The Europa radiation environment is harsh, and this ionizing radiation around Jupiter is much more severe than that produced by the GPHS radioisotope heat source. As part of the DOE/NASA Stirling technology assessment, GRC evaluated the radiation effects on the organic materials in the Stirling convertor (Golliher, 2000). These included piston bearing coatings, piston bumpers, and alternator adhesives and electrical insulations. In each case, a radiation-hard organic material has been identified. These materials have been incorporated into the TDC convertors that STC is providing to NASA GRC. Each organic material in the TDC's will now be further examined for meeting the functionality and radiation requirements. The testing of the GRC TDC's will help verify this functionality. Individual bench tests will also be identified and conducted as necessary. Thin-film X-ray radiation testing will be conducted on the selected Xylan piston coating and on other organics that may not be fully qualified. 
An independent reliability assessment of the TDC was performed by GRC as part of the DOE/NASA Stirling technology assessment (Thieme, 2000b). The conclusion was that there was sufficient relevant data and that all of the design issues were well understood and could be managed within the current quality practices of the aerospace industry. NASA GRC will now provide support to the reliability efforts being led by Westinghouse for DOE. This GRC work will be supported as needed by the NASA GRC Risk Management Office.

\section{CONCLUDING REMARKS}

The Department of Energy, NASA Glenn Research Center (GRC), and Stirling Technology Company are developing a free-piston Stirling convertor for a Stirling radioisotope power system (SRPS) to provide spacecraft on-board electric power for NASA deep space missions. The SRPS has recently been identified for potential use on the Europa Orbiter and Solar Probe Space Science missions and is also now being considered for unmanned Mars rovers.

NASA GRC is conducting an in-house project to assist in developing the Stirling convertor for readiness for space qualification and mission implementation. Key inputs have been provided by GRC to a DOE/NASA technology assessment that has led to the current mission possibilities for the Stirling system. Test facilities for convertor performance testing, magnet aging, and structural benchmark testing of the heater head have been established or are nearing completion. Further key results for launch environment characterizations, reduction in electromagnetic interference (EMI), independent performance verification, convertor life assessment, and permanent magnet aging characterization are expected in the near future.

\section{REFERENCES}

Bartolotta, P.; Bowman, R.; Krause, D.; and Halford, G., "Long-Term Durability Analysis of a 100,000-Hour Stirling Power Convertor Heater Head," Proceedings of the $35^{\text {th }}$ Intersociety Energy Conversion Engineering Conference, Las Vegas, NV, 2000 (AIAA 2000-2841).

Furlong, R. and Shaltens, R., "Technology Assessment of DOE's 55-We Stirling Technology Demonstrator Convertor (TDC)," Proceedings of the $35^{\text {th }}$ Intersociety Energy Conversion Engineering Conference, Las Vegas, NV, 2000 (AIAA-2000-3018).

Geng, S.M.; Schwarze, G.E.; and Niedra, J.M., "A 3-D Magnetic Analysis of a Linear Alternator for a Stirling Power System," Proceedings of the $35^{\text {th }}$ Intersociety Energy Conversion Engineering Conference, Las Vegas, NV, 2000 (AIAA 2000-2838).

Golliher, E.L. and Pepper, S.V., "Organic Materials Ionizing Radiation Susceptibility for the Outer Planets/Solar Probe Radioisotope Power Source," Proceedings of the $35^{\text {th }}$ Intersociety Energy Conversion Engineering Conference, Las Vegas, NV, 2000 (AIAA 2000-3077).

Goodnight, T.W.; Hughes, W.O.; and McNelis, M.E., "Dynamic Capability of an Operating Stirling Convertor," Proceedings of the $35^{\text {th }}$ Intersociety Energy Conversion Engineering Conference, Las Vegas, NV, 2000 (AIAA 2000-2839).

Schreiber, J.G., "Assessment of the Free-Piston Stirling Convertor as a Long Life Power Convertor for Space," Proceedings of the $35^{\text {th }}$ Intersociety Energy Conversion Engineering Conference, Las Vegas, NV, 2000 (AIAA-2000-3021).

Tew, R.C. and Geng, S.M., "Overview of NASA Supported Stirling Thermodynamic Loss Research,” NASA TM-105690, 1992.

Thieme, L.G.; Qiu, S.; and White, M.A., "Technology Development for a Stirling Radioisotope Power System," in Space Technology and Applications International Forum 2000, edited by M.S. El-Genk, AIP Conference Proceedings 504, American Institute of Physics, NASA TM-2000-209791, 2000a.

Thieme, L.G. and Schreiber, J.G., "NASA GRC Technology Development Project for a Stirling Radioisotope Power System," Proceedings of the $35^{\text {th }}$ Intersociety Energy Conversion Engineering Conference, Las Vegas, NV, 2000 (AIAA-2000-2840), NASA/TM-2000-210246, 2000b.

White, M.A.; Qiu, S.; Augenblick, J.; Peterson, A.; and Faultersack, F., "Positive Results from a Free-Piston Stirling Engine Technology Demonstration Program for Advanced Radioisotope Space Power Systems," Proceedings of the $35^{\text {th }}$ Intersociety Energy Conversion Engineering Conference, Las Vegas, NV, 2000 (AIAA 2000-3023). 
Public reporting burden for this collection of information is estimated to average 1 hour per response, including the time for reviewing instructions, searching existing data sources, gathering and maintaining the data needed, and completing and reviewing the collection of information. Send comments regarding this burden estimate or any other aspect of this collection of information, including suggestions for reducing this burden, to Washington Headquarters Services, Directorate for Information Operations and Reports, 1215 Jefferson Davis Highway, Suite 1204, Arlington, VA 22202-4302, and to the Office of Management and Budget, Paperwork Reduction Project (0704-0188), Washington, DC 20503.
1. AGENCY USE ONLY (Leave blank)
2. REPORT DATE
3. REPORT TYPE AND DATES COVERED
December 2000
Technical Memorandum

4. TITLE AND SUBTITLE

Update on the NASA GRC Stirling Technology Development Project

6. $\operatorname{AUTHOR}(\mathrm{S})$

Lanny G. Thieme and Jeffrey G. Schreiber 5. FUNDING NUMBERS

National Aeronautics and Space Administration

John H. Glenn Research Center at Lewis Field

Cleveland, Ohio 44135-3191

WU-839-20-00-00

WU-755-A4-14-00

9. SPONSORING/MONITORING AGENCY NAME(S) AND ADDRESS(ES)

National Aeronautics and Space Administration

Washington, DC 20546-0001

8. PERFORMING ORGANIZATION

REPORT NUMBER

E-12550

10. SPONSORING/MONITORING

AGENCY REPORT NUMBER

NASA TM-2000-210592

11. SUPPLEMENTARY NOTES

Prepared for the Space Technology and Applications International Forum sponsored by the American Institute of Physics, Albuquerque, New Mexico, February 11-15, 2001. Responsible person, Lanny G. Thieme, organization code 5490, 216-433-6119.

12a. DISTRIBUTION/AVAILABILITY STATEMENT

12b. DISTRIBUTION CODE

Unclassified - Unlimited

Subject Categories: 20 and 44

Distribution: Nonstandard

Available electronically at http://gltrs.grc.nasa.gov/GLTRS

This publication is available from the NASA Center for AeroSpace Information, 301-621-0390.

13. ABSTRACT (Maximum 200 words)

The Department of Energy, NASA Glenn Research Center (GRC), and Stirling Technology Company (STC) are developing a free-piston Stirling convertor for a Stirling radioisotope power system (SRPS) to provide spacecraft on-board electric power for NASA deep space missions. The SRPS has recently been identified for potential use on the Europa Orbiter and Solar Probe Space Science missions. Stirling is also now being considered for unmanned Mars rovers. NASA GRC is conducting an in-house project to assist in developing the Stirling convertor for readiness for space qualification and mission implementation. As part of this continuing effort, the Stirling convertor will be further characterized under launch environment random vibration testing, methods to reduce convertor electromagnetic interference (EMI) will be developed, and an independent performance verification will be completed. Convertor life assessment and permanent magnet aging characterization tasks are also underway. Substitute organic materials for the linear alternator and piston bearing coatings for use in a high radiation environment have been identified and have now been incorporated in Stirling convertors built by STC for GRC. Electromagnetic and thermal finite element analyses for the alternator are also being conducted. This paper discusses the recent results and status for this NASA GRC in-house project.

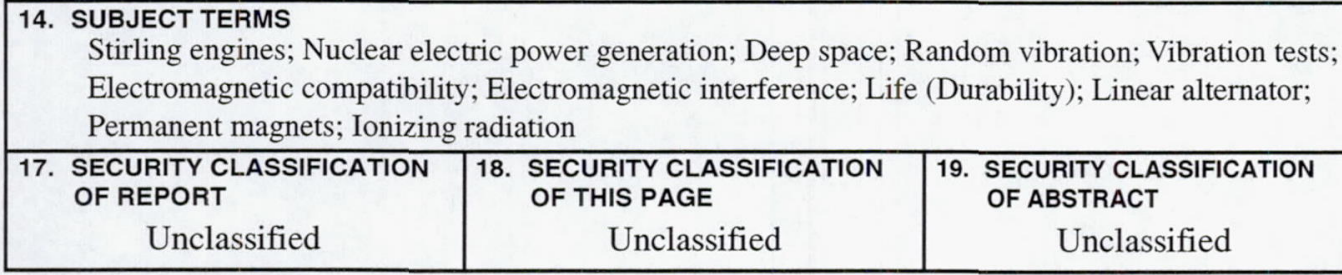

\begin{tabular}{|c|c|}
\hline & $\begin{array}{c}\text { NUMBER OF PAGES } \\
12\end{array}$ \\
\hline & PRICE CODE \\
\hline & $\mathrm{A} 03$ \\
\hline & LIMITATION OF ABSTRACT \\
\hline
\end{tabular}

